\title{
Salpingoscopy in tubal endometriosis
}

\author{
Ludovico Muzii • Riccardo Marana
}

Received: 16 February 2010 /Accepted: 29 March 2010/Published online: 20 April 2010

(C) Springer-Verlag 2010

Keywords Endometriosis · Fallopian tube .

Female infertility $\cdot$ Salpingoscopy

A 35-year-old woman underwent diagnostic laparoscopy for primary infertility of 3-year duration, without associated pain symptoms. No ovulatory or male factors of infertility were present. She had previously undergone hysterosalpingography, which had revealed bilateral tubal patency 18 months before laparoscopy.

Laparoscopy revealed endometriosis implants on the right tube, with mild peritoneal scarring (Fig. 1). Both tubes were readily patent at blue dye injection. Minimal peritoneal endometriosis was present on the ipsilateral posterior leaf of the broad ligament and on the ipsilateral ovary.

\section{Muzii $(\bowtie)$}

Department of Obstetrics and Gynecology,

Università Campus Bio-Medico,

Via A del Portillo 21,

00128 Rome, Italy

e-mail: 1.muzii@unicampus.it

R. Marana

Department of Obstetrics and Gynecology,

Università Cattolica del Sacro Cuore,

Rome, Italy

R. Marana

Istituto Scientifico Internazionale Paolo VI,

Università Cattolica del Sacro Cuore,

Rome, Italy
The surgeon faced the decision whether to treat or not the implants visible on the tubal serosa. If, on one side, there is sound scientific evidence that the peritoneal endometriosis implants should be treated [1], the treatment of tubal implants on the other side is not clear cut, being this a rare occurrence. Surgical treatment of implants on the tubal serosa, either by excision or ablation, may in fact carry the risk of creating additional scarring and retraction.

The surgeon decided to perform intraoperative salpingoscopy, with a $2.9-\mathrm{mm}$ diagnostic hysteroscope and a $3.7-\mathrm{mm}$ single-flow diagnostic sheath introduced through an accessory port. Salpingoscopy is still routinely used in our departments in case of tubal disease, despite the fact that it is not generally included in the evaluation of the infertile couple elsewhere [2]. Lately, we have been using a small-caliber hysteroscope, as in this case, instead of the original instrumentation for salpingoscopy [3], since it is more readily available and does not need dedicated instruments. The endoscopic evaluation of the tube (Fig. 2) revealed a normal tubal mucosa (class 1 according to Brosens' classification [3]), no evidence of endometriosis in the tubal mucosa, and no evidence of stenosis of the tubal wall. It was, therefore, decided to leave the tubal endometriosis untreated.

Three months after surgery, the patient spontaneously conceived an intrauterine pregnancy.

Declaration of interest The authors report no conflicts of interest. The authors alone are responsible for the content and writing of the paper. 


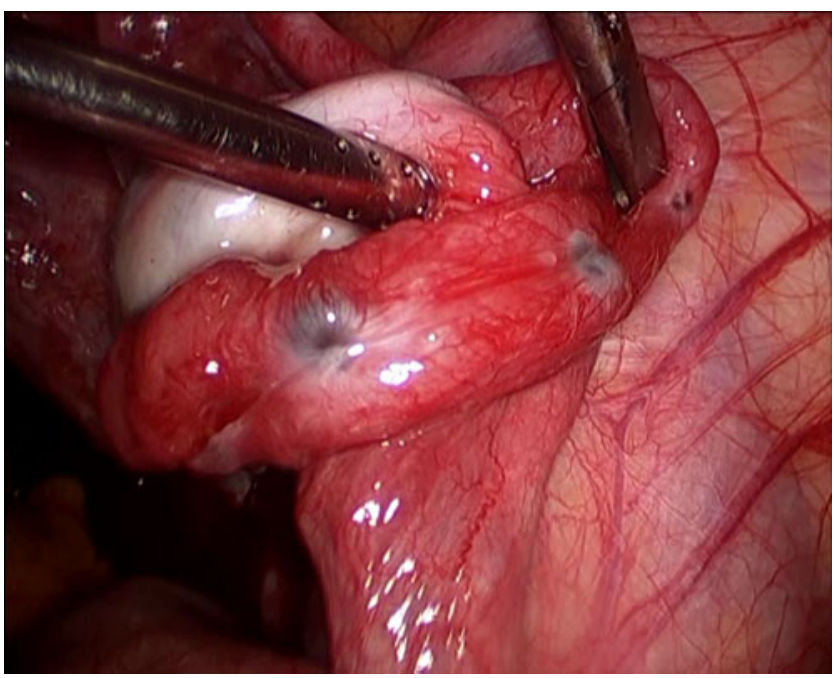

Fig. 1 Endometriosis implants on the tubal serosa as seen at laparoscopy

\section{References}

1. Jacobson TZ, Barlow DH, Koninckx PR et al (2002) Laparoscopic surgery for subfertility associated with endometriosis. Cochrane Database Syst Rev (4):CD001398

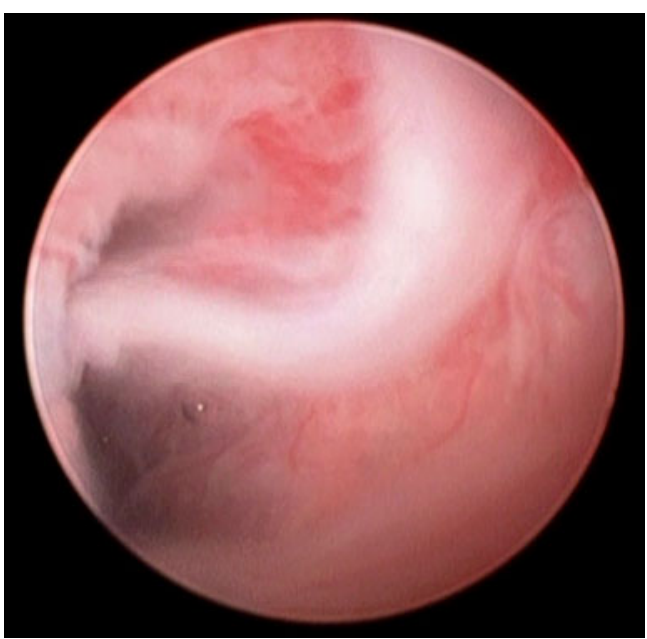

Fig. 2 Salpingoscopy with visualization of the tubal mucosa at the level of the serosal endometriosis revealed no intraluminal disease

2. Marana R, Ferrari S, Astorri AL, Muzii L (2008) Indications to tubal reconstructive surgery in the era of IVF. Gynecol Surg 5:85-91

3. Brosens IA, Boeckx W, Delattin P (1987) Salpingoscopy: a new preoperative diagnostic tool in tubal infertility. $\mathrm{Br} \mathrm{J}$ Obstet Gynaecol 94:768-773 